clinical responsibility. It would thus be possible for organisations such as the Nuffield Nursing Homes to satisfy themselves that a doctor without a consultant NHS appointment is a suitable person to be given admitting and operating privileges. This seems a mighty small nut for the sledge-hammer which is proposed.

An entitlement to register a certificate of accreditation voluntarily with the GMC would furnish the necessary evidence. To those who would argue that only if the GMC has control of the bodies issuing such certificates can their registration be effective one must point out the precedent of the GMC registering higher qualifications in the past without having any form of control over the bodies concerned.
ADDENDUM-Since this paper was written the Council for Postgraduate Medical Education in England and Wales has issued a statement ${ }^{6}$ broadly in agreement with the views I have expressed here.

\section{References}

1 Committee of Inquiry into the Regulation of the Medical Profession, Report, Cmnd 6018. London, HMSO, 1975. (Merrison Report.) ${ }^{2}$ British Medical fournal, 1975, 2, 155.

3 British Medical fournal, 1973, 3, suppl p 29.

4 European Communities Act 1972. London, HMSO, 1972.

5 British Medical fournal Supplement, 1973, 2, p 163.

${ }^{6}$ Brittsh Medical fournal, 1976, 1, 166.

\title{
Medical Training
}

\section{General physician and specialist training in thoracic medicine}

\author{
M G BRITTON, J V COLLINS
}

British Medical fournal, 1976, 1, 331-332

The need for physicians with special experience in chest diseases has been the subject of constant reappraisal since $1960 .^{1-3}$ In 1968 the Central Health Services Committee ${ }^{2}$ recommended that each district general hospital should have a department of respiratory medicine staffed by physicians who would participate in providing general medical services.

Respiratory diseases cause up to a third of surgery visits in general practice ${ }^{4}$ and major loss of work-time, ${ }^{5}$ yet there is little data about the demands which respiratory diseases make in hospital practice on which future plans for providing specialists may be based.

We have reviewed the work load created by patients with respiratory diseases presenting to hospital doctors in order to assess the need for specialist experience of respiratory diseases within a general medical service, and the value of these patients in educating junior hospital doctors in the specialty.

\section{Patients and methods}

St Leonard's Hospital is a small hospital in Hoxton providing adult general medical and surgical services. Acute medical admissions to the 98 medical beds are shared between three consultants acting as general physicians but holding joint academic appointments with the medical college at St Bartholomew's Hospital. The junior hospital staff consists of a medical registrar, two senior house officers, and three preregistration house physicians. The hospital has its own accident and emergency unit which is shared with the neighbouring Metropolitan Hospital, which takes two-fifths of the medical work load.

A prospective study to discover the demands which respiratory diseases make in hospital practice was conducted on patients admitted

\section{St Leonard's Hospital, London N1}

M G BRITTON, MB, MRCP, medical registrar (present address: London Hospital, Whitechapel, London E1 1BB)

J V COLLINS, MD, MRCP, consultant physician to hospital between 1 October 1973 and 30 September 1974 in whom an acute respiratory illness was considered the main reason for admission. Those patients admitted from outpatients or electively for investigations were excluded from the study.

\section{Results}

The total number of all medical admissions during the period of the study was 1501 (HAA); of these, $1203(80 \%)$ were acute as judged by our survey. Respiratory illnesses accounted for $15.6 \%$ of these acute admissions (table I) and the nature of these respiratory illnesses is analysed in table II. A review of the HAA statistics

TABLE I-Causes of acute medical admission to hospital from 1 October 1973 to 30 September 1974

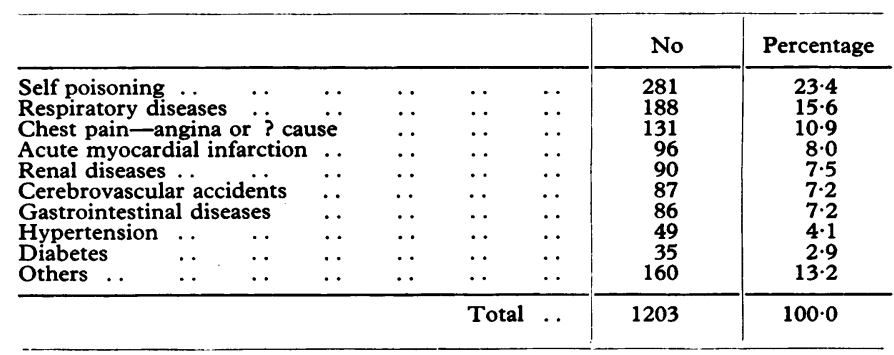

TABLE II-Respiratory illnesses causing acute admission to hospital from 1 October 1973 to 30 September 1974

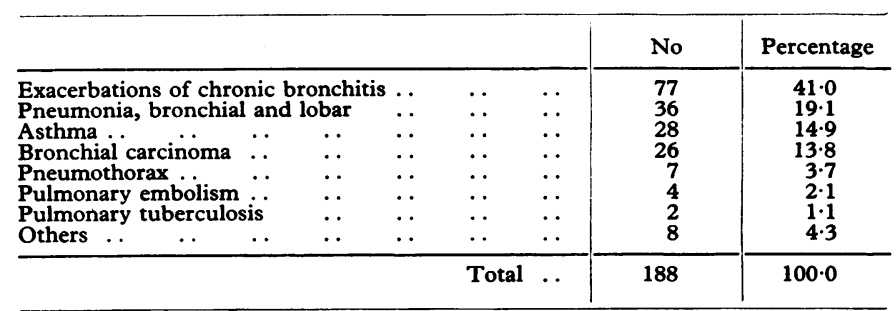


suggested a much larger respiratory work load $\left(20 \cdot 2^{\circ}{ }_{\circ}\right)$. This was partly due to the inclusion of patients admitted from outpatients or electively for investigations and others who developed respiratory illnesses while in hospital.

We expected that respiratory illnesses would account for about a quarter of acute medical admissions and the observed figure of $15.6^{\circ}$ o was somewhat surprising. This lower figure may be partly explained by the strict criteria used for the inclusion of patients in the study and by the unusually mild winter (1973-4). There was no influenza epidemic and no red yellow alerts were issued by the emergency bed service.

\section{Training posts and prospects}

The Specialist Advisory Committee on Respiratory Medicine ${ }^{6}$ recommended that four years' clinical experience at senior registrar (or initially registrar) level should be gained, of which two years should be in general medicine and two in thoracic medicine. By 1974, however, the average time spent as a senior registrar before appointment to consultant posts in thoracic medicine was $2 \cdot 2$ years (Department of Health and Social Security).

Figures adapted from Ridehalgh's ${ }^{3}$ data show that 209 consultant posts in thoracic medicine or their equivalent should fall vacant in England and Wales during 1974-84, an average of 21 posts a year. The number of senior registrars in specialist training in thoracic medicine in September 1974 was 18 in England and Wales (DHSS). This is a notable increase since 1969, when there were only eight, but still not sufficient to supply the expected vacancies with well-trained personnel (see table III).

TABLE III-Posts in thoracic medicine in England and Wales 1969 and 1974 $(D H S S)$

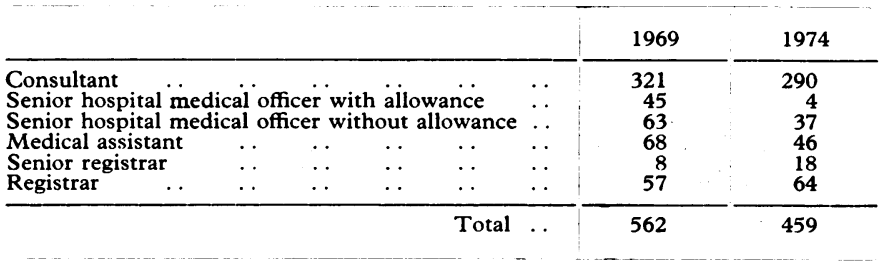

\section{Discussion}

Our study has shown that the management of respiratory illnesses forms a substantial part of the work load of general physicians, and on this evidence the inclusion of a physician with a special interest in thoracic medicine on the staff of general hospitals seems advisable. Our results suggest that suitable experience of many common respiratory disorders should be gained during general medical training. But experience of the kind recommended for specialist training, ${ }^{6}$ which includes study

of the physiology, pharmacology, and immunology of lung diseases, is unlikely to be gained outside specialist centres.

We consider that training posts in thoracic medicine should be tailored to provide comprehensive coverage of the subjects that are likely to be insufficiently covered in general medical experience gained at registrar level. These specialised aspects of thoracic medicine should be provided in senior registrar appointments, during which the incumbents would rotate through the appropriate departments, and out of necessity the time spent gaining general medical experience in the higher grade might have to be less than the suggested two years. It would seem appropriate that posts in specialised centres for thoracic medicine which are presently designated registrar grade should be reviewed with the possibility of upgrading them. If future needs are to be met we calculate that it is necessary to increase the number of senior registrar posts in thoracic medicine in England and Wales to 36. These changes would minimise losses of registrars with some experience of the specialty who subsequently enter other specialties because of the lack of suitable senior registrar posts in thoracic medicine. As our study has shown, this would not preclude those not intending a career in thoracic medicine from gaining sufficient experience of the commoner respiratory diseases during their general medical training.

The need to co-ordinate plans for thoracic medicine on a regional basis is apparent, and since the reorganisation of the NHS the funding of training posts and the control of consultant posts have been decentralised and are now the responsibility of the regional manpower committees. Despite present economic difficulties these committees must be encouraged to continue the policy of expansion of the senior registrar grade in thoracic medicine, and they should be aware of the need for a physician with an interest in thoracic medicine in every district general hospital.

We thank the junior medical staff of St Leonard's Hospital, especially Drs R Lambert, N Fairhurst, and S Matthews, for their help with collecting data for the study, and Mrs Christine Payne for invaluable secretarial help.

\section{References}

1 Central Health Services Council, Report by Standing Tuberculosis Advisory Committee, HM(60)44, London, HMSO, 1960.

2 Central Health Services Council, Future of the Chest Services. London, HMSO, 1968.

3 Ridehalgh, F, British Medical fournal, 1971, 1, 161

4 Fry, J, British Medical fournal, 1957, 2, 1453.

${ }^{5}$ Heath, R B, Recent Advances in Medicine. London, Churchill, 1973.

${ }^{6}$ Joint Committee on Higher Medical Training. Recommendations on Training in Respiratory Medicine. London, Royal College of Physicians, 1973.

Do heparin injections reduce the incidence of coronary thrombosis in those who already have had an attack, or would continuing any other anticoagulant agents be beneficial?

There is impressive evidence of the advantages of heparin in treating thromboembolic disease. Its use for preventing recurrent attacks of myocardial infarction may be advocated on the following bases: heparin is superior to oral anticoagulant drugs in preventing experimental clot; increased platelet stickiness is decreased by heparin but unaffected by dicoumarol; heparin inhibits thrombin forming and thus tends to prevent thrombus development. Heparin also removes fat from the blood by stimulating the formation of lipoprotein lipase, probably in the endothelium of the arterial wall. The relation of lipaemia to thrombus formation is well established; lipaemia increases platelet adhesiveness, red cell aggregation, plasma viscosity, and decreases fibrinolysis. Heparin also increases oxygen uptake by the tissues. Lipaemia decreases coronary blood flow and myocardial oxygen consumption, which are restored to normal with the process of plasma-clearing by heparin. In spite of such a clear rationale, the case for long-term heparin treatment to prevent recurrent attacks of myocardial infarction remains to be proved: large, well-controlled multicentre trials are needed.

\section{How long can a virus live on a dead body?}

A very difficult question, as I do not think this matter has been studied in any detail. Although viruses can multiply only in living cells they may survive in cells for some time after death. The time a live virus will survive will depend on three main factors: the time since death when tests for presence of virus are carried out; the temperature at which the body has been kept; and the type of virus concerned. Viruses may be recovered from tissues at necropsy within 24-48 hours, provided that the body has been refrigerated. This would apply to influenza viruses and enteroviruses such as poliovirus, but others such as measles and rubella tend to be more sensitive to changes in temperature. Some viruses, particularly smallpox and hepatitis, are very resistant to heat, and because of their virulence special precautions should be taken in carrying out necropsies on people who have died from these diseases. 